\title{
BMJ Open Multilevel predictors of controlled CD4 count and blood pressure in an integrated chronic disease management model in rural South Africa: a panel study
}

\author{
Soter Ameh (1D , ${ }^{1,2,3}$ Francesc X Gómez-Olivé, ${ }^{2,4}$ Kathleen Kahn, ${ }^{2,4,5}$ \\ Stephen Tollman, ${ }^{2,4,5}$ Kerstin Klipstein-Grobusch ${ }^{6,7}$
}

To cite: Ameh S, GómezOlivé $\mathrm{FX}$, Kahn $\mathrm{K}$, et al. Multilevel predictors of controlled CD4 count and blood pressure in an integrated chronic disease management model in rural South Africa: a panel study. BMJ Open 2020;10:e037580. doi:10.1136/ bmjopen-2020-037580

- Prepublication history and additional material for this paper is available online. To view these files, please visit the journal online (http://dx.doi.org/10. 1136/bmjopen-2020-037580).

Received 08 February 2020 Revised 28 September 2020 Accepted 06 October 2020

Check for updates

(c) Author(s) (or their employer(s)) 2020. Re-use permitted under CC BY-NC. No commercial re-use. See rights and permissions. Published by BMJ.

For numbered affiliations see end of article.

Correspondence to

Dr Soter Ameh;

sote_ameh@yahoo.com

\section{ABSTRACT}

Objective In 2011, The National Department of Health introduced the Integrated Chronic Disease Management (ICDM) model as a pilot programme in selected primary healthcare facilities in South Africa. The objective of this study was to determine individual-level and facility-level predictors of controlled CD4 count and blood pressure (BP) in patients receiving treatment for HIV and hypertension, respectively.

Design A panel study.

Setting and participants This study was conducted in the Bushbuckridge Municipality, South Africa from 2011 to 2013. Facility records of patients aged $\geq 18$ years were retrieved from the integrated chronic disease management (ICDM) pilot $(n=435)$ and comparison facilities $(n=443)$ using a three-step probability sampling process. CD4 count and BP control are defined as CD4 count $>350$ cells/ $\mathrm{mm}^{3}$ and $\mathrm{BP}<140 / 90 \mathrm{~mm} \mathrm{Hg}$. A multilevel Least Absolute Shrinkage and Selection Operator binary logistic regression analysis was done at a $5 \%$ significance level using STATA V.16.

Primary outcome measures CD4 (cells $/ \mathrm{mm}^{3}$ ) count and $\mathrm{BP}(\mathrm{mm} \mathrm{Hg})$.

Results Compared with the comparison facilities, patients receiving treatment in the pilot facilities had increased odds of controlling their CD4 count $(\mathrm{OR}=5.84,95 \% \mathrm{Cl}$ 3.21-8.22) and $\mathrm{BP}(\mathrm{OR}=1.22,95 \% \mathrm{Cl} 1.04-2.14)$. Patients aged $50-59(0 \mathrm{R}=6.12,95 \% \mathrm{Cl} 2.14-7.21)$ and $\geq 60$ ( $\mathrm{OR}=7.59,95 \% \mathrm{Cl} 4.75-11.82)$ years had increased odds of controlling their CD4 counts compared with those aged $18-29$ years. Likewise, patients aged $40-49(0 R=5.73$, $95 \% \mathrm{Cl} 1.98-8.43), 50-59$ (OR=7.28, 95\% Cl 4.33-9.27) and $\geq 60(0 R=9.31,95 \% \mathrm{Cl} 5.12-13.68)$ years had increased odds of controlling their BP. In contrast, men had decreased odds of controlling their $\mathrm{CD} 4$ count $(\mathrm{OR}=0.12$, $95 \% \mathrm{Cl} 0.10-0.46)$ and $\mathrm{BP}(\mathrm{OR}=0.21,95 \% \mathrm{Cl} \mathrm{0.19-0.47)}$ than women.

Conclusion The ICDM model had a small but significant effect on BP control, hence, the need to more effectively leverage the HIV programme for optimal BP control in the setting.
Strengths and limitations of this study

- First study in sub-Saharan Africa to determine multilevel predictors of CD4 count and blood pressure control in an integrated chronic disease model.

- Use of existing facility records or data to determine multilevel predictors of controlled CD4 count and blood pressure.

- Use of a comparison study arm to investigate the effect(s) of potential confounders on the control of CD4 count and blood pressure.

- Unavailable or missing facility-level data for patients with HIV (viral load for antiretroviral treatment (ART) monitoring 52\% missing, duration of illness, ART regimen); patients with hypertension (bio-behavioural risk factors, body mass index antihypertension drugs); and unavailability of complete data on staffing, patient load and medication supply chain.

- The criteria for which health providers used to classify adherence of patients to antihypertension medication as 'good' or 'poor' could not be ascertained.

\section{INTRODUCTION}

Two in three global deaths are due to noncommunicable diseases (NCDs), causing more deaths than all other causes combined, ${ }^{1}$ and the majority (three-quarter) of these deaths occur in low-income and middleincome countries (LMICs). ${ }^{1}$ NCDs could have a remarkable effect on the global disease burden and healthcare because they are the leading cause of mortality in China, Ghana, India, Mexico, Russia and South Africa, the six middle-income countries that host $42 \%$ of the world's 1.4 billion people aged 50 years and older. Of these six countries, South Africa has the highest prevalence of hypertension. ${ }^{2}$

Hypertension is the main risk factor for cardiovascular diseases (CVDs) globally ${ }^{3}$ and the latter is the leading cause of mortality due 
to NCDs. A household Study on global AGEing and adult health (WHO SAGE) showed that $43 \%$ of adults in South Africa are hypertensive, of which $58 \%$ are unaware. ${ }^{4}$ It is estimated that nearly half of all deaths in South Africa are due to NCDs. ${ }^{5}$

The high NCD-related morbidity and mortality in South Africa have been attributed to poor management of NCDs, especially hypertension, within the healthcare system ${ }^{67}$ and fragmented chronic disease services. ${ }^{89}$ Poor management of hypertension is a consequence of nonsystematic implementation of treatment guidelines; nonconsultative process with relevant stakeholders in the development of guidelines; scepticism about the durability of the guideline; conflict with local practices; health system problems (eg, drug stock-out) and patient beliefs. ${ }^{6}$ Poor knowledge of patients about their conditions and drug prescriptions not being recorded in the medical records have also been identified as factors adversely affecting optimal management of hypertension. ${ }^{7}$ These could have implications for South Africa's public healthcare system which has yet to adapt to the long-term continuity of care. ${ }^{89}$

The commonalities in the prevention, management and control of HIV/AIDS and NCDs make it feasible to tackle South Africa's high dual burden of HIV/AIDS and NCDs. ${ }^{10}$ First, hypertension and HIV may not show symptoms at the early stages of onset. This implies that their management may require a shift from the acute care model, which is largely dependent on the manifestation of symptoms and signs. Second, both chronic diseases require regular clinic appointments and medication adherence; hence, the need for appointment and medication reminder systems. ${ }^{11}$ Finally, the expanded use of antiretroviral treatments (ARTs) increases life expectancy, which is defined as the probable number of years a person will live after a given age as determined by the mortality rate in a given geographic area. ${ }^{12}$ Consequently, there has been an increase in the burden of age-associated noncommunicable comorbidities (eg, CVDs) among people living with HIV (PLWH) comparable with the general population. ${ }^{11} 13$ An additional physiologic pathway to this is that ART increases the risk of lipidaemia. Therefore, PLWH and who are on ARTs have an increased likelihood of developing CVDs. ${ }^{14}$

Primary and secondary prevention measures targeting individual (behavioural) risk factors such as tobacco use, harmful alcohol use, unhealthy diets and physical inactivity have been advocated as measures to reduce NCDrelated morbidity and mortality. ${ }^{15}$ Yet, one in four adult South Africans has raised blood pressure (BP), and two in three of these adults with raised $\mathrm{BP}$ are not receiving antihypertensive treatment ${ }^{16}$; hence, the need for health system interventions to further tackle the high and rising burden of hypertension.

Based on the evidence that integrated management of chronic diseases leads to improvement in patient health outcomes (eg, CD4 count, glycosylated haemoglobin and BP),${ }^{17}$ the Joint United Nations Programme on HIV/
AIDS has recommended a comprehensive and integrated approach to the delivery of chronic disease care. ${ }^{11}$ This approach requires leveraging HIV programmes to support or scale-up services for NCDs.

In this regard, the government of South Africa developed a 4-year strategic plan. ${ }^{18}$ One of the strategies of the framework is improved control of NCDs through health systems strengthening and reform. A key objective of this strategy is primary healthcare (PHC) re-engineering which entails the integration of NCDs into the primary healthcare package. ${ }^{18}$ In 2011, The National Department of Health introduced the Integrated Chronic Disease Management (ICDM) model as a pilot programme in selected PHC facilities in Gauteng, North West and Mpumalanga Provinces. ${ }^{19}$ The ICDM model leverages the successful vertical HIV programme for supporting or scaling up services for NCDs.

The model has facility and community components. Health facilities are reorganised to provide 'one-stopshop' services in designated chronic care areas. ${ }^{19}$ The HIV Counselling and Testing campaign, the largest in the world, which has already tested over 13 million people for HIV, also offers an excellent opportunity to conduct NCD screenings on patients who attend clinics, particularly for patients on ARTs. ${ }^{18}$

The community component conducts population screening for NCDs and links diagnosed cases and highrisk persons to facility care for optimal health outcomes. A PHC outreach team, made up of a nurse and community healthcare workers, visits patients' homes to provide home-based care and link clinic defaulters back to care. ${ }^{19} 20$

Since the initiation of the ICDM model, there is a paucity of literature on multilevel predictors of key patient health outcomes. The objective of this study was to determine individual-level and facility-level predictors of controlled CD4 count and BP in patients receiving treatment for HIV and hypertension, respectively.

\section{METHODS \\ Study setting}

The setting of the study was in 12 PHC facilities in the Bushbuckridge Municipality in Ehlanzeni district situated in Mpumalanga Province, northeast of South Africa. The ICDM model was implemented in 17 of the 38 PHC facilities in the municipality at the time this study started in June 2013. Of these 17 facilities implementing the integrated model of care, 7 situated in the Agincourt subdistrict were purposively selected into the ICDM model arm of the study (ie, the ICDM pilot facilities) because they served the population in the Agincourt subdistrict where the population has been under surveillance by the Medical Research Council/Wits Agincourt Research Unit using a Health and Socio-demographic Surveillance System since 1992. At the time this study was commenced, there were 90000 people in 16000 households living in 27 villages. ${ }^{21}$ Of the remaining 21 PHC facilities situated 
outside the Agincourt subdistrict not implementing the integrated model of care, 5 were randomly selected into the comparison arm of the study (ie, the comparison facilities).

\section{Study design and population}

This panel study was conducted in the selected 12 PHC facilities in the Bushbuckridge Municipality and is a component of the broader mixed methods research used to evaluate the quality of the integrated model of care. $^{22}$ The inclusion criteria were age 18 years and above and being on treatment in these health facilities for the markers of chronic diseases in the study area (HIV, hypertension and diabetes) from January 2011. Patients who were transferred between these facilities during the 30-month study period (January 2011-June 2013) were excluded.

\section{Sample size estimation}

A minimum sample size of 430 participants was estimated in each study arm after adjusting for $15 \%$ attrition in a panel study, using a two proportion sample size formula ${ }^{23}$ with a two-sided distribution at 5\% significance level $\left(Z_{\alpha / 2}=1.96\right)$ and $90 \%$ power $\left(Z_{\beta}=1.28\right)$. An effect size of $10 \%$ is needed to detect a significant difference between the ICDM pilot and the comparison health facilities in controlling patients' BP having leveraged the vertical HIV programme for hypertension treatment in the integrated model of care. The population prevalence of hypertension in the study area $(43 \%)^{24}$ was assumed to be the prevalence of hypertension in the comparison health facilities $\left(\mathrm{P}_{1}\right)$ where the integrated model was not being implemented. The expectation is that the prevalence of hypertension in the ICDM pilot facilities $\left(\mathrm{P}_{2}\right)$ would be lower (33\%), hence, the effect size of $10 \%$ as earlier specified.

\section{Sampling of study participants}

The study participants were recruited through a threestep process (see online supplemental file 1). First, the proportionate sampling technique was used to recruit a specific number of patients from each of the 12 health facilities. Second, the patients recruited in each health facility were stratified by HIV, hypertension and diabetes cases using the sampling frame specific to each facility. Finally, from the disease-specific clinical appointment roster, systematic sampling was used to recruit patients based on the earlier stratified cases until the estimated sample size in each facility was achieved. The sampling interval was determined by the disease-specific sampling fraction. Hence, 435 and 443 patients were recruited from the ICDM facilities and comparison facilities, respectively.

\section{Data collection}

After patient recruitment in June 2013, information on viral load, CD4 count, BP and glycosylated haemoglobin were retrospectively retrieved from patients' facility records over a period of 4 months. South Africa's policy on eligibility criteria for ART initiation during the time this study was commenced were WHO clinical stage 3 or
4 , CD4 count $\leq 350$ cells $/ \mathrm{mm}^{3}$, and pregnancy or breastfeeding status. ${ }^{25}$ Patients with HIV on ART had their viral load and CD4 count tests repeated every 12 and 6 months, respectively, for the purposes of monitoring their responses to treatment. There was scanty data on viral load. In this study, CD4 count control is defined as CD4 count $>350$ cells $/ \mathrm{mm}^{3}$. Adherence to ART at every clinic visit was assessed by a pill count, and having a pill count of more than $95 \%$ was considered good. The ART regimen used in the health facilities at the time of this study is shown in the online supplemental file 2.

In this study, hypertension is defined as being on antihypertensive medication; or systolic BP (SBP) $\geq 140 \mathrm{~mm}$ $\mathrm{Hg}$ or diastolic BP (DBP) $\geq 90 \mathrm{~mm} \mathrm{Hg}$ on three separate measurements 2-3 days apart. ${ }^{25}$ Control of BP is defined as $\mathrm{BP}<140 / 90 \mathrm{~mm} \mathrm{Hg}$ for patients with hypertension on antihypertensive medication as specified in the Primary Care (PC) 101 management guideline. ${ }^{25}$ Nurses subjectively assessed and documented adherence to antihypertensive medication as 'good' or 'poor' by counting the number of medicines brought forth after the last visit. The online supplemental file 2 shows the hypertension treatment guideline used at the time this study was conducted.

\section{Data management and statistical analysis}

We hypothesised that the integrated HIV and hypertension model of care could influence changes in the BP of patients with hypertension receiving antihypertensive medication. Statistical analysis of the data was done using STATA V.16. Predictors of CD4 count and BP control were examined at two levels: individual (age, gender, education, looking for a paid job, reception of grant, presence of multimorbidity and adherence) and facility factors/ covariates (type of facility and referral).

Propensity score matching was done to balance the effects of age and chronic disease status that differed between the study groups. ${ }^{26}$ The binary outcome dependent variables (controlled $\left(>350\right.$ cells $/ \mathrm{mm}^{3}$ ) versus uncontrolled $\left(\leq 350\right.$ cells $\left./ \mathrm{mm}^{3}\right)$ CD4 count and controlled $(<140 / 90 \mathrm{~mm} \mathrm{Hg})$ versus uncontrolled $(\geq 140 / 90 \mathrm{~mm}$ $\mathrm{Hg}) \mathrm{BP}$ ) were coded as 0 for 'uncontrolled' and 1 for 'controlled'. A logistic Least Absolute Shrinkage and Selection Operator regression model was fit at a $5 \%$ significance level with all the covariates for each of the dependent variables to determine predictors of CD4 count and BP control adjusting for the study arms (clusters) where patients received treatment. A constant, lambda $(\lambda)$, was specified as the regularisation parameter to adjust the amount of the coefficient shrinkage. We used crossvalidation to select the best $\lambda$ that minimised the crossvalidation function (Bayes Information Criterion).

Variables that significantly predicted CD4 count and BP control in the adjusted analysis were those whose $95 \%$ CI values excluded the null value of 1 . Due to scanty data, viral load results could not be used for ART monitoring. Regression analysis could not be done for patients with diabetes because of their small number $(n=4)$. 


\section{Ethical clearance}

This research was conducted in accordance with the best ethical standards with written informed consent obtained from the study participants and confidentiality assured.

\section{Patient and public involvement}

It was not appropriate or possible to involve patients or the public in the design, or conduct, or reporting, or dissemination plans of our research.

\section{RESULTS}

Generally, there were more patients $\geq 50$ years of age receiving care in the ICDM model facilities than the comparison facilities ( $67 \%$ vs $43 \%$ ). The ICDM facilities provided care to more patients with hypertension $(48 \%$ vs $21 \%$ ), whereas the comparison facilities offered care to more patients with HIV (64\% vs $32 \%)$ (table 1$)$.

Table 2 shows that patients in the age groups 50-59 $(\mathrm{OR}=6.12,95 \% \mathrm{CI} 2.14-7.21)$ and $\geq 60(\mathrm{OR}=7.59,95 \% \mathrm{CI}$ 4.75-11.82) years had increased odds of having their CD4 counts controlled compared with those aged 18-29 years. Likewise, patients with HIV receiving care in the ICDM model facilities had a sixfold increased odds $(\mathrm{OR}=5.84$, 95\% CI 3.21-8.22) of having their CD4 counts controlled compared with those receiving care in the facilities not implementing the integrated model of care. In contrast, men had decreased odds ( $\mathrm{OR}=0.12,95 \%$ CI $0.10-0.46)$ of having their CD4 counts controlled than women.

In the adjusted model (table 3), age, gender and receiving care in the ICDM model facilities were predictors of a controlled BP (SBP $<140$ or DBP $<90 \mathrm{~mm} \mathrm{Hg}$ ). Compared with patients in the age group 18-29years, those in the age groups $40-49(\mathrm{OR}=5.73$, 95\% CI 1.98$8.43), 50-59(\mathrm{OR}=7.28,95 \%$ CI $4.33-9.27)$ and $\geq 60$ $(\mathrm{OR}=9.31,95 \%$ CI 5.12-13.68) years had increased odds of having their BP controlled. Similarly, patients with hypertension receiving care in the ICDM model facilities had increased odds ( $\mathrm{OR}=1.29,95 \%$ CI 1.04-2.14) of having their BP controlled. In contrast, men had decreased odds $(\mathrm{OR}=0.21,95 \%$ CI $0.19-0.47)$ of controlling their BP than women.

\section{DISCUSSION}

The main findings showed that receiving treatment in the ICDM pilot facilities and increasing age were associated with a higher chance of controlling patients CD4 count and $\mathrm{BP}$ while men were less likely than women to have their CD4 count and BP controlled. We are unaware of any study in Africa that determined multilevel predictors of CD4 count and BP control in an integrated chronic disease model. The main strengths of this study were the use of existing facility records or data to determine multilevel predictors of controlled CD4 count and BP and the use of a comparison study arm to investigate the effect(s) of potential confounders on the control of CD4 count and BP.
Table 1 Socio-demographic characteristics and facility visits of the study population in the Bushbuckridge municipality, 2011-2014

\begin{tabular}{|c|c|c|c|}
\hline \multirow[b]{2}{*}{ Variables } & \multicolumn{3}{|c|}{ Study groups, $\mathbf{n}(\%)$} \\
\hline & $\begin{array}{l}\text { ICDM model } \\
\text { group } \\
(\mathrm{N}=435)\end{array}$ & $\begin{array}{l}\text { Comparison } \\
\text { group } \\
(\mathrm{N}=443)\end{array}$ & $\begin{array}{l}\text { Total } \\
(\mathrm{N}=878)\end{array}$ \\
\hline \multicolumn{4}{|l|}{ Age group, years } \\
\hline $18-29$ & $19(4.5)$ & $39(8.9)$ & $58(6.8)$ \\
\hline $30-39$ & $60(14.3)$ & $119(27.0)$ & $179(20.8)$ \\
\hline $40-49$ & $59(14.1)$ & $92(20.9)$ & $151(17.6)$ \\
\hline $50-59$ & $84(20.1)$ & 85 (19.3) & $169(19.6)$ \\
\hline$\geq 60$ & $197(47.0)$ & $105(23.9)$ & $302(35.2)$ \\
\hline \multicolumn{4}{|l|}{ Gender } \\
\hline Women & $363(84.4)$ & $368(83.6)$ & $731(84.0)$ \\
\hline Men & $67(15.6)$ & $72(16.4)$ & $139(16.0)$ \\
\hline \multicolumn{4}{|c|}{ Education (completed years) } \\
\hline $\begin{array}{l}\text { No formal } \\
\text { education }\end{array}$ & $172(39.6)$ & $167(37.7)$ & $339(38.6)$ \\
\hline $1-6$ & $174(40.0)$ & $169(38.1)$ & $343(39.1)$ \\
\hline$>6$ & $71(16.3)$ & $73(16.5)$ & $144(16.4)$ \\
\hline Missing & $18(4.1)$ & $34(7.7)$ & $52(5.9)$ \\
\hline \multicolumn{4}{|c|}{ Looking for a paid job } \\
\hline Yes & $126(29.0)$ & $120(27.0)$ & $246(28.0)$ \\
\hline No & $291(66.9)$ & $301(68.0)$ & $592(67.4)$ \\
\hline Missing & $18(4.1)$ & $22(5.0)$ & $40(4.6)$ \\
\hline \multicolumn{4}{|c|}{ Chronic disease status } \\
\hline Hypertension & $210(48.3)$ & $91(20.5)$ & $301(34.3)$ \\
\hline HIV & $141(32.4)$ & $282(63.7)$ & $423(48.2)$ \\
\hline Diabetes & $2(0.5)$ & $2(0.5)$ & $4(0.5)$ \\
\hline Multimorbidity* & $82(18.8)$ & $68(15.3)$ & $150(17.0$ \\
\hline \multicolumn{4}{|c|}{ No. of hypertension clinic visits } \\
\hline Minimum & 1 & 1 & 1 \\
\hline Maximum & 40 & 34 & 40 \\
\hline Average & 14 & 6 & 10 \\
\hline \multicolumn{4}{|c|}{ Number of HIV clinic visits } \\
\hline Minimum & 1 & 1 & 1 \\
\hline Maximum & 45 & 39 & 45 \\
\hline Average & 19 & 7 & 13 \\
\hline
\end{tabular}

*Multimorbidity is defined as having more than one chronic disease.

The rural Bushbuckridge Municipality has an agestandardised HIV prevalence (26\% in women and $19 \%$ in men) that is higher $\operatorname{than}^{27}$ the estimated overall HIV prevalence of $13 \%$ among the South African population ${ }^{28}$ as well as a high population hypertension prevalence characterised by a gender difference $(40 \%$ in women and $30 \%$ in men). An earlier study in the Bushbuckridge Municipality showed a changing demographic as younger 
Table 2 Multilevel predictors of CD4 count control among 429 patients with HIV receiving care in health facilities in the Bushbuckridge municipality, 2011-2014

CD4 count control ( $>350$ cells $/ \mathrm{mm}^{3}$ )

Variables

Adjusted OR (95\% Cl)

Individual-level factors

Age group, years

\begin{tabular}{|c|c|}
\hline $18-29$ & 1 \\
\hline 30-39 & $0.83(0.21-2.22)$ \\
\hline $40-49$ & $1.62(0.49-3.99)$ \\
\hline $50-59$ & $6.12(2.14-7.21)^{\star}$ \\
\hline$\geq 60$ & $7.59(4.75-11.82)^{*}$ \\
\hline \multicolumn{2}{|l|}{ Gender } \\
\hline Women & 1 \\
\hline Men & $0.12(0.10-0.46)^{\star}$ \\
\hline \multicolumn{2}{|l|}{ Education (completed years) } \\
\hline No formal education & 1 \\
\hline $1-6$ & $1.01(0.31-2.09)$ \\
\hline$>6$ & $1.02(0.57-1.43)$ \\
\hline \multicolumn{2}{|l|}{ Looking for a paid job } \\
\hline No & 1 \\
\hline Yes & $0.73(0.48-1.18)$ \\
\hline \multicolumn{2}{|l|}{ Reception of grant } \\
\hline None & 1 \\
\hline Disability & $1.36(0.74-2.38)$ \\
\hline HIV & $1.71(0.66-2.21)$ \\
\hline Old age & $1.94(0.82-2.10)$ \\
\hline \multicolumn{2}{|l|}{ Multimorbidity } \\
\hline No & 1 \\
\hline Yes & $2.53(0.61-4.12)$ \\
\hline \multicolumn{2}{|l|}{ Adherence to ART } \\
\hline No & 1 \\
\hline Yes & $1.03(0.04-1.21)$ \\
\hline \multicolumn{2}{|l|}{ Health facility-level factors } \\
\hline \multicolumn{2}{|l|}{ Type of health facility } \\
\hline $\begin{array}{l}\text { Not implementing the ICDM } \\
\text { model }\end{array}$ & 1 \\
\hline Implementing the ICDM model & $5.84(3.21-8.22)^{\star}$ \\
\hline \multicolumn{2}{|c|}{ Referral of patients to the doctors/hospitals } \\
\hline No & 1 \\
\hline Yes & $1.16(0.72-3.01)$ \\
\hline
\end{tabular}

*Statistically significant variable.

people migrate to urban areas for work and leave behind an older population. ${ }^{29}$ This change of demographic characteristic could be partly responsible for the high prevalence of hypertension in the municipality, thus, the need for prioritisation of chronic disease care ${ }^{30}$ Hence,
Table 3 Multilevel predictors of BP control among 450 patients with hypertension receiving treatment in health facilities in the Bushbuckridge municipality, 2011-2014

BP control (BP $<140 / 90 \mathrm{~mm} \mathrm{Hg}$ )

Variables Adjusted OR $(95 \% \mathrm{Cl})$

Individual-level factors

Age group, years

$\begin{array}{ll}18-29 & 1 \\ 30-39 & 1.02(0.30-3.12) \\ 40-49 & 5.73(1.98-8.43) \\ 50-59 & 7.28(4.33-9.27)^{\star} \\ \geq 60 & 9.31(5.12-13.68)^{\star}\end{array}$

Gender

$\begin{array}{ll}\text { Women } & 1 \\ \text { Men } & 0.21(0.19-0.47)^{*}\end{array}$

Education (completed years)

No formal education 1

$1-6 \quad 1.19(0.47-2.18)$

$>6 \quad 1.21(0.51-1.79)$

Looking for a paid job

No 1

Yes

$0.59(0.43-1.16)$

Reception of grant

\begin{tabular}{ll} 
None & 1 \\
\hline Disability & $1.87(0.44-5.04)$ \\
\hline HIV & $0.05(0.01-1.26)$ \\
\hline Old age & $2.00(0.63-4.99)$ \\
\hline Multimorbidity & 1 \\
\hline No & $0.72(0.48-1.02)$ \\
\hline Yes & 1 \\
\hline Adherence to antihypertensive medication \\
$\begin{array}{l}\text { No } \\
\text { Yes }\end{array}$ \\
$\begin{array}{l}\text { Health facility-level factors } \\
\text { Type of health facility }\end{array}$ \\
$\begin{array}{l}\text { Not implementing the ICDM } \\
\text { model }\end{array}$ \\
$\begin{array}{l}\text { Implementing the ICDM model } \\
\text { Referral of patients to the doctors/hospitals }\end{array}$ \\
\hline $\begin{array}{l}\text { No } \\
\text { Yes }\end{array}$ & $1.29(1.04-2.14)$ \\
\hline
\end{tabular}

*Statistically significant variable.

$\mathrm{BP}$, blood pressure; ICDM, integrated chronic disease management.

implementing the pilot ICDM programme in Ehlanzeni district, one of the three districts where the model was initiated in South Africa, was a timely intervention. ${ }^{19}$ 
Similar to the findings of an integrated care model for HIV/AIDS, hypertension and diabetes used in Cambodia, which showed increasing median CD4 counts in a cohort of patients on ART, ${ }^{17}$ the ICDM model pilot facilities had higher odds of controlling patients' CD4 counts than the comparison facilities. This may partly be attributed to the reduction of HIV stigma which was reported by the Operational Managers of the ICDM pilot facilities. ${ }^{31}$ The perception of these facility managers, who are also trained professional nurses, was that having patients with HIV and hypertension receive care in the same consultation room without identifying who was a patient with HIV may have led to increased uptake of HIV services. This could imply that one of the purposes of integrating HIV and NCD services (ie, to reduce HIV stigma by concealing the identity of patients with HIV in the facilities) may have been achieved.

Although the ICDM pilot facilities had a significantly higher odds (OR=1.64, 95\% CI 1.11-2.41) of controlling BP compared with the comparison facilities, the observed odds were lower than that for CD4 count control (1.64 vs 6.55) and corroborates a previous study in the setting which reported a suboptimal level of control of hypertension $(45.8 \%)$ at the population level. ${ }^{32}$ Our finding does not entirely corroborate the Cambodian study that showed a remarkable improvement in BP control. We attribute this to facility and system factors: (1) South Africa's vertical HIV programme is not well administratively integrated into the horizontal general health system ${ }^{9}$; (2) five of the eight identified priority dimensions of care (waiting time, referral system, appointment system, prepacking of medicines and defaulter tracing) used to leverage the HIV programme for NCD services did not reflect their intended constructs for quality care in the ICDM model ${ }^{22}$; (3) service users and providers in the ICDM pilot facilities reported staff shortage, malfunctioning BP apparatus, stock-out of antihypertensive medication and an increased workload resulting from integrated care $^{31}$ as well as (4) crowding-out of routine training activities which typically occur before or during the implementation of an intervention programme. ${ }^{33}$

This implies that the purpose of leveraging the HIV programmes, tools and systems to scale up services for NCDs is yet to be fully achieved. Achieving optimal BP control in the ICDM model requires more extensive diagonal integration or leveraging of resources provided for the HIV vertical programme to enhance the platforms for delivering a comprehensive horizontal health system in which the ICDM model is embedded. Specific to hypertension care, health facility-specific structural (staff shortage, broken BP equipment and antihypertensive medication stock-outs) and process (increased workload) factors must be addressed for optimal BP control.

This study showed that increasing age and being a female patient were associated with an increased likelihood of controlling BP and CD4 counts after adjusting for education, looking for a paid job, reception of grants, having more than one chronic condition, adherence to medication and being referred to a doctor or higher level of care. This finding is consistent with that of Health and Aging in Africa: A Longitudinal Study of an INDEPTH Community in South Africa which was conducted at the same time and in the same setting as ours. ${ }^{32}$ Furthermore, two independent studies conducted-10 years apart-in $1998^{34}$ and $2008^{35}$ consistently showed that hypertension control was higher in women than men, with increasing age and female sex being positive determinants. ${ }^{35} 36$ The higher odds of BP control among older people and women observed in our study can be attributed to an increasing level of awareness and more contact with healthcare as was previously reported in the study setting and elsewhere in South Africa. ${ }^{32} 35$ Therefore, health education interventions targeting men and younger patients could contribute to better BP control in the study setting.

Study findings must be interpreted in the light of the limitations imposed by the use of facility data which were incomplete or unavailable due to missing laboratory results of $\mathrm{CD} 4$ counts and viral load, missing records of $\mathrm{BP}$ measurements, unavailability of comparative data on staffing and lack of information on the medication supply chain.

This study contributes to ongoing national and global debates on an integrated health systems approach. The key findings of our research could have implications for scaling up implementation of the ICDM model in South Africa and for the planning of an integrated chronic care in other LMICs.

\section{Author affiliations}

${ }^{1}$ Department of Community Medicine, Faculty of Medicine, College of Medical Sciences, University of Calabar, Calabar, Nigeria

${ }^{2}$ Medical Research Council/Wits University Rural Public Health and Health

Transitions Research Unit (Agincourt), Faculty of Health Sciences, School of Public Health, University of the Witwatersrand, Johannesburg, South Africa

${ }^{3}$ Department of Global Health and Population, Harvard T.H. Chan School of Public Health, Harvard University, Boston, Massachusetts, USA

${ }^{4}$ The International Network for the Demographic Evaluation of Populations and Their Health in Developing Countries (INDEPTH), Accra, Ghana

${ }^{5}$ Umeå Centre for Global Health Research, Epidemiology and Global Health, Umeå University, Umeå, Sweden

${ }^{6}$ Division of Epidemiology and Biostatistics, School of Public Health, University of the Witwatersrand, Johannesburg, South Africa

${ }^{7}$ Julius Global Health, Julius Center for Health Sciences and Primary Care, University Medical Center Utrecht, Utrecht, The Netherlands

Acknowledgements The authors are grateful to Latonya S Wilson for writing support, and Sulaimon Afolabi, Chodziwadziwa Whiteson Kabudula and Nkosinati Masilela for assistance with data management.

Funding This work was supported by the Agincourt Health and Socio-Demographic Surveillance System, a node of the South African Population Research Infrastructure Network (SAPRIN) and is supported by the National Department of Science and Innovation, the Medical Research Council and the University of the Witwatersrand, South Africa, and the402 Wellcome Trust, UK (grants 058893/Z/99/A;

069683/Z/02/Z; 085477/Z/08/Z;403 085477/B/08/Z); Fogarty International Centre of the National Institutes of Health [D43404 TW008330]; and African Doctoral Dissertation Research Fellowship Programme award to the corresponding author. Funding for the article processing charge for this manuscript was provided by the Lown Scholars Program in Cardiovascular Health, Department of Global Health and Population, Harvard T.H. Chan School of Public Health, Harvard University, Boston, Massachusetts, USA.

Competing interests None declared.

Patient consent for publication Not required. 
Ethics approval Ethical clearance for this study was received from the Committee for Research on Human Subjects (Medical) of the University of the Witwatersrand, Johannesburg, South Africa (Ref No. M120943), and the Mpumalanga Provincial Research and Ethics Committee.

Provenance and peer review Not commissioned; externally peer reviewed.

Data availability statement Data are available upon reasonable request. Data are available upon reasonable request.

Supplemental material This content has been supplied by the author(s). It has not been vetted by BMJ Publishing Group Limited (BMJ) and may not have been peer-reviewed. Any opinions or recommendations discussed are solely those of the author(s) and are not endorsed by BMJ. BMJ disclaims all liability and responsibility arising from any reliance placed on the content. Where the content includes any translated material, BMJ does not warrant the accuracy and reliability of the translations (including but not limited to local regulations, clinical guidelines, terminology, drug names and drug dosages), and is not responsible for any error and/or omissions arising from translation and adaptation or otherwise.

Open access This is an open access article distributed in accordance with the Creative Commons Attribution Non Commercial (CC BY-NC 4.0) license, which permits others to distribute, remix, adapt, build upon this work non-commercially, and license their derivative works on different terms, provided the original work is properly cited, appropriate credit is given, any changes made indicated, and the use is non-commercial. See: http://creativecommons.org/licenses/by-nc/4.0/.

\section{ORCID iD}

Soter Ameh http://orcid.org/0000-0002-8449-6423

\section{REFERENCES}

1 World Health Organization, Geneva. Global status report on noncommunicable diseases 2010. Description of the global burden of NCDS, their risk factors and determinants, 2014. Available: http:// whqlibdoc.who.int/publications/2011/9789240686458_eng.pdf

2 He W, Muenchrath NM, Kowal P. Shades of gray: a cross-country study of health and well-being of the older populations in SAGE countries, 2007-2010. International populations report 2012, 2020. Available: https://www.nia.nih.gov/sites/default/files/d7/p95-12-01. pdf

3 Lim SS, Vos T, Flaxman AD, et al. A comparative risk assessment of burden of disease and injury attributable to 67 risk factors and risk factor clusters in 21 regions, 1990-2010: a systematic analysis for the global burden of disease study 2010. Lancet 2012;380:2224-60.

4 Ware LJ, Chidumwa G, Charlton K, et al. Predictors of hypertension awareness, treatment and control in South Africa: results from the WHO-SAGE population survey (wave 2). J Hum Hypertens 2019;33:157-66.

5 World Health Organization, Geneva. Noncommunicable diseases country profiles 2014, 2015. Available: http://www.who.int/nmh/ countries/zaf en.pdf?ua=1

6 Daniels A, Biesma R, Otten J, et al. Ambivalence of primary health care professionals towards the South African guidelines for hypertension and diabetes. S Afr Med J 2000;90:1206-11.

7 Steyn K, Levitt NS, Patel M, et al. Hypertension and diabetes: poor care for patients at community health centres. S Afr Med J 2008;98:64-70.

8 Tollman SM, Kahn K, Sartorius B, et al. Implications of mortality transition for primary health care in rural South Africa: a populationbased surveillance study. The Lancet 2008;372:893-901.

9 Kawonga M, Fonn S, Blaauw D. Administrative integration of vertical HIV monitoring and evaluation into health systems: a case study from South Africa. Glob Health Action 2013;6:19252.

10 Mayosi BM, Flisher AJ, Lalloo UG, et al. The burden of noncommunicable diseases in South Africa. Lancet 2009;374:934-47.

11 Joint United Nations Programme on HIV/AIDS. New York. chronic care of HIV and non-communicable diseases: how to leverage the HIV experience, 2011. Available: http://www.unaids.org/en/ media/unaids/contentassets/documents/unaidspublication/2011/ 20110526 JC2145 Chronic care of HIV-1.pdf

12 Life expectancy. Mosby's medical dictionary, 8th edition, 2009. Available: http://medical-dictionary.thefreedictionary.com/life+ expectancy
13 Kitahata MM, Tegger MK, Wagner EH, et al. Comprehensive health care for people infected with HIV in developing countries. BMJ 2002;325:954-7.

14 Smart T. Hiv and non-communicable diseases (NCDS), 2011. Available: http://www.aidsmap.com/HIV-and-non-communicablediseases-NCDs/page/2094965/ (13 June 2020).

15 Yusuf S, Hawken S, Ounpuu S, et al. Effect of potentially modifiable risk factors associated with myocardial infarction in 52 countries (the INTERHEART study): case-control study. Lancet 2004;364:937-52.

16 Health Systems Trust. South African health review, 2016. Available: https://www.hst.org.za/publications/South\%20African\%20Health\% 20Reviews/SAHR\%202016.pdf

17 Janssens B, Van Damme W, Raleigh B, et al. Offering integrated care for HIV/AIDS, diabetes and hypertension within chronic disease clinics in Cambodia. Bull World Health Organ 2007;85:880-5.

18 National Department of Health, Pretoria. Strategic plan for the prevention and control of non-communicable diseases 2013-17, 2013. https://extranet.who.int/ncdccs/Data/ZAF_B3_NCDs_STRAT_ PLAN 1_29_1_3\%5B2\%5D.pdf

19 Mahomed $\overline{\mathrm{OH}}$, Asmall S, Freeman M. An integrated chronic disease management model: a diagonal approach to health system strengthening in South Africa. J Health Care Poor Underserved 2014;25:1723-9.

20 Mahomed $\mathrm{OH}$, Asmall S, Voce A. Sustainability of the integrated chronic disease management model at primary care clinics in South Africa. Afr J Prim Health Care Fam Med 2016;8:1248.

21 Kahn K, Collinson MA, Gómez-Olivé FX, et al. Profile: Agincourt health and socio-demographic surveillance system. Int J Epidemiol 2012;41:988-1001.

22 Ameh S, Gómez-Olivé FX, Kahn K, et al. Relationships between structure, process and outcome to assess quality of integrated chronic disease management in a rural South African setting: applying a structural equation model. BMC Health Serv Res 2017;17:229.

23 Kirkwood BR, Steane JAC. Essential medical statistics. 2nd ed. Oxford: Blackwell publishing company, 2003: 413-28.

24 Thorogood M, Connor MD, Hundt GL, et al. Understanding and managing hypertension in an African sub-district: a multidisciplinary approach. Scand J Public Health Suppl 2007;69:52-9.

25 Department of Health. Republic of South Africa. primary care 101: symptom-based integrated approach to the adult in primary care. 2013/2014. https://www.goinginternational.eu/wp/de/primary-care101/ (27 October 2020).

26 Leuven E, Sianesi B. PSMATCH2: Stata module to perform full Mahalanobis and propensity score matching, common support graphing, and covariate imbalance testing, 2014. Available: http:// ideas.repec.org/c/boc/bocode/s432001.html

27 Clark SJ, Gómez-Olivé FX, Houle B, et al. Cardiometabolic disease risk and HIV status in rural South Africa: establishing a baseline. BMC Public Health 2015;15:135.

28 Africa SS. Mid year population estimates, 2018. Available: https:// www.statssa.gov.za/publications/P0302/P03022018.pdf

29 Kahn K, Tollman SM, Collinson MA, et al. Research into health, population and social transitions in rural South Africa: data and methods of the Agincourt health and demographic surveillance system. Scand J Public Health Supp/ 2007;69:8-20.

30 Ameh S, Gómez-Olivé FX, Kahn K, et al. Predictors of health care use by adults 50 years and over in a rural South African setting. Glob Health Action 2014;7:24771.

31 Ameh S, Klipstein-Grobusch K, D'ambruoso L, et al. Quality of integrated chronic disease care in rural South Africa: user and provider perspectives. Health Policy Plan 2016;7:czw118.

32 Jardim TV, Reiger S, Abrahams-Gessel S, et al. Hypertension management in a population of older adults in rural South Africa. $J$ Hypertens 2017;35:1283-9.

33 Gilson L. Health policy and systems research: a methodology reader. Geneva: World Health Organization, 2012.

34 Steyn K, Bradshaw D, Norman R, et al. Determinants and treatment of hypertension in South Africans: the first demographic and health survey. S Afr Med J 2008;98:376-80.

35 Peltzer K, Phaswana-Mafuya N. Hypertension and associated factors in older adults in South Africa. Cardiovasc J S Afr 2013;24:67-71.

36 Schneider M, Bradshaw D, Steyn K, et al. Poverty and noncommunicable diseases in South Africa. Scand J Public Health 2009;37:176-86. 